\title{
CULTURA, DIVERSIDADE E DIRETRIZES PARA A EDUCAÇÃO ESCOLAR INDÍGENA
}

\author{
Maria Rosemi Araujo do NASCIMENTO ${ }^{i}$
}

\begin{abstract}
RESUMO
Este artigo trata de concepções de Cultura, Diversidade e Educação Escolar Indígena. Também descreve acerca da Legislação da Educação Escolar Indígena e os avanços nas duas últimas décadas. É um recorte da tese "Formação de Professores e Currículo: uma prática em Ciências da Natureza para a diversidade com alunos indígenas em escola não indígena na cidade de Manaus", cujo objetivo foi analisar a prática do ensino do componente curricular Ciências da Natureza para indígenas inseridos em escolas não indígenas. Trata-se de um estudo de caso com abordagem qualitativa. A metodologia contempla observação direta, caminhada pedagógica, observação sistemática não participante, aula compartilhada, questionário e entrevista semiestruturada. Os resultados apresentaram invisibilidade dos alunos indígenas no currículo e ensino de Ciências da Natureza descontextualizado da cultura indígena, que não é contemplada nas práticas pedagógicas.
\end{abstract}

PALAVRAS-CHAVE: Cultura; Diversidade; Educação Escolar Indígena.

\section{CULTURE, DIVERSITY AND GUIDELINESS FOR INDIGENOUS SCHOOL EDUCATION}

\begin{abstract}
This article deals with concepts of Culture, Diversity and Indigenous School Education. It also describes about the Indigenous School Education Legislation and the advances in the last two decades. It is an excerpt from the thesis "Teacher Education and Curriculum: a practice in Natural Sciences for diversity with indigenous students in a non-indigenous school in the city of Manaus", whose objective was to analyze the teaching practice of the Natural Sciences curriculum component for indigenous people inserted in non-indigenous schools. This is a case study with a qualitative approach. The methodology includes direct observation, pedagogical walk, systematic non-participant observation,shared class, questionnaire and semi-structured interview.The results showed invisibility of indigenous students in the curriculum and teaching of Natural Sciences out of context of indigenous culture, which is not included in pedagogical practices.
\end{abstract}

KEYWORDS: Culture; Diversity; Indigenous School Education.

\footnotetext{
${ }^{\text {i }}$ Doutorado em Educação: Currículo pela PUC-SP. Professora da Educação Básica da Secretaria Municipal de Educação de Manaus. E-mail: profrosearaujo@hotmail.com. 


\begin{abstract}
RESUMEN
Este artículo trata los conceptos de Cultura, Diversidad y Educación Escolar Indígena. También describe sobre la Legislación de Educación Escolar Indígena y los avances en las últimas dos décadas. Es un extracto de la tesis "Formación y Currículo Docente: una práctica en Ciencias Naturales para la diversidad con estudiantes indígenas en una escuela no indígena de la ciudad de Manaus", cuyo objetivo fue analizar la práctica docente del componente curricular de Ciencias Naturales para indígenas. insertado en escuelas no indígenas. Este es un estudio de caso con un enfoque cualitativo. La metodología incluye observación directa, caminata pedagógica, observación sistemática no participante, clase compartida, cuestionario y entrevista semiestructurada. Los resultados evidenciaron la invisibilidad de los estudiantes indígenas en el currículo y la enseñanza de las Ciencias Naturales fuera del contexto de la cultura indígena, que no está incluida en las prácticas pedagógicas.
\end{abstract}

PALABRAS CLAVE: Cultura; Diversidad; Educación Escolar Indígena.

\title{
1 INTRODUÇÃO
}

O texto a seguir trata de uma reflexão acerca dos conceitos e concepções de Cultura e Diversidade, suas convergências e divergências apresentadas por alguns teóricos como Hall (2011), Bhabha (1998), Johnson (2010), Laraia (2009), Geertz (1989), Malinowski (2009), entre outros, que nos trazem possibilidades para uma compreensão dessas terminologias. Julgamos importante conhecer os fundamentos que envolvem esses termos, uma vez que Cultura, Diversidade e Educação, neste caso, Educação Escolar Indígena, são conceitos interligados, integrados entre si e manifestos no Currículo em forma de concepções, vividas no contexto das escolas.

Para uma reflexão um pouco mais aprofundada, trataremos também das diversas legislações e diretrizes que estabelecem obrigatoriedade e regulamentação para a Educação Escolar Indígena. A legislação vigente relacionada a esta modalidade da Educação Nacional Brasileira, alcançou um bom avanço nas duas últimas décadas, entretanto, precisamos analisar o quanto houve de acesso desses alunos na escola e o quanto a legislação vem contribuindo, de fato, para a escolaridade desses brasileiros.

O estudo do qual derivou este artigo traz uma importante contribuição para a comunidade acadêmica, pois fomenta o interesse por mais pesquisas dessa natureza envolvendo as práticas pedagógicas que contemplem alunos indígenas em escolas não indígenas. Também estimula a sociedade a valorizar as diversas culturas que se apresentam na escola, mas principalmente para os indígenas, para quem o estudo traz uma possibilidade de 
reconhecimento e visibilização nos espaços escolares.

Assim sendo, passaremos a nossa abordagem a seguir, trabalhando em dois tópicos, sendo o primeiro "Cultura e Diversidade: Conceitos, Concepções e Interações” e o segundo “Educação Escolar Indígena: Legislações e Diretrizes Nacionais”, conforme segue.

\section{METODOLOGIA}

O estudo investigativo sobre Cultura, Diversidade e as diretrizes para educação escolar indígena faz parte da tese de Doutorado "Formação de Professores e Currículo: uma prática em Ciências da Natureza para a diversidade com alunos indígenas em escola não indígena na cidade de Manaus", em que o objetivo geral foi analisar a prática do ensino do componente curricular Ciências da Natureza quando ministrado aos indígenas inseridos em escolas não indígenas. $\mathrm{O}$ problema constituiu-se pela questão "como os professores dos três primeiros anos do Ensino Fundamental ensinam Ciências da Natureza para alunos indígenas inseridos em escolas não indígenas?” A partir daí trabalhamos no referencial teórico, do qual este artigo faz parte. Para tanto, nos conduzimos para uma metodologia pautada nos preceitos da pesquisa qualitativa, uma vez que apresentamos nesta etapa da tese uma pesquisa de caráter teórico, fundamentada em estudos também teóricos, a partir de documentos oficiais do Ministério da Educação e de concepções e conceitos de estudiosos que se debruçam sobre a temática, dentre eles destacamos o que Chizzotti (2010, p. 79) assevera sobre a abordagem qualitativa como "parte do fundamento de que há uma relação dinâmica entre o mundo real e o sujeito, [...], um vínculo indissociável entre o mundo objetivo e a subjetividade do sujeito", em que esta relação dinâmica envolve e transforma o sujeito que pesquisa.

Durante o processo de estudo fomos descobrindo indicativos fundamentais para o desenvolvimento da pesquisa, pois tanto os estudiosos dos conceitos de Cultura quanto os documentos oficiais da educação nacional brasileira consultados apresentaram considerada relevância para a construção do diálogo ora apresentado neste artigo, considerando os conceitos de Cultura, Diversidade e também as diretrizes para educação escolar indígena.

As concepções sobre Culturas apresentadas pelos autores como Laraia (2009), Malinowski (2009), entre outros que aparecem neste trabalho, nos permitiram estabelecer um parâmetro, bem como uma interação ou um distanciamento entre as diversas visões 
estabelecidas nos estudos levantados, o que nos permitiu uma análise crítica em torno do assunto aqui discutido.

O trabalho que apresentamos caracteriza uma revisão bibliográfica, pois apresenta a visão de diversos autores e ainda de documentos oficiais da educação escolar indígena brasileira. Tais estudos possibilitaram ampliar nossa visão e também apresentar esta pesquisa por meio de uma discussão dinâmica. A leitura que fazemos desse processo é de um panorama envolvendo Cultura, Diversidade, seus conceitos, concepções e interações e também educação escolar indígena à luz da legislação e das diretrizes para esta demanda em nosso país.

\section{CULTURA E DIVERSIDADE: CONCEITOS, CONCEPÇÕES E INTERAÇÕES}

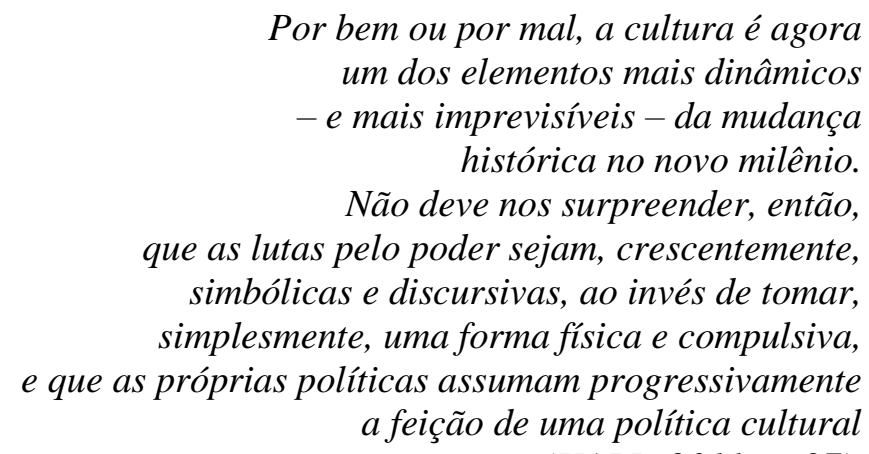

(HALL, 2011, p. 97).

O texto de Hall (2011), em epígrafe, sobre a cultura como um dos elementos mais dinâmicos e imprevisíveis do novo milênio, se constitui em um marco fundamental no processo de mudança social na contemporaneidade, ao balizar as lutas políticas, enquanto poder simbólico, as quais definem as novas feições assumidas pela sociedade. O respeito à diversidade cultural precisa estar presente não só nos discursos, mas também nas ações de lutas, numa constante perseverança em direção ao princípio de igualdade e de democracia, desejado por muitos. E, a democracia nada mais é do que o espaço individual e coletivo, que todos devem ocupar para apropriação do lugar de pertencimento no mundo.

Nesse contexto, o trabalho acerca das concepções e conceitos de Cultura e Diversidade envolve, antes de qualquer coisa, pensar o humano, observando-se que todos têm direito às mesmas oportunidades e encaminhamentos em relação aos seus costumes, acessos aos bens culturais, científicos e religiosos como preservação e garantia da dignidade da pessoa humana.

Segundo Bhabha (1998, p. 19), 
O que é teoricamente inovador e politicamente crucial é a necessidade de passar além das narrativas e subjetividades originárias e iniciais e de focalizar aqueles momentos ou processos que são produzidos na articulação de diferenças culturais.

Vale ressaltar que este é um dos conceitos para a educação na diversidade com a perspectiva intercultural. Nesse sentido, conhecer alguns fundamentos sobre esses termos é um passo importante para compreendermos a necessidade de abordarmos tais questões quando falamos de Educação e de Currículo, uma vez que toda prática pedagógica está envolvida de sentidos e significados que revelam a intencionalidade da ação. Assim sendo, a cultura deve ser estudada em sua totalidade, respeitando localidade e contexto, pois o valor está nas raízes de uma civilização, podendo ser concebida como um produto social, que representa uma coletividade e/ou uma tradição, uma forma de luta para transformação e conquista social e, não simplesmente como uma criatividade individual (JOHNSON, 2010).

Com base nesse contexto, é possível afirmar que existe uma diversidade cultural, que pode ser determinada por questões biológicas ou geográficas o que possibilita diferentes comportamentos mesmo dentro de um mesmo território ou região. Entretanto, para Laraia (2009, p. 24), tais “diferenças existentes entre os homens [e mulheres], portanto, não podem ser explicadas [exclusivamente] em termos das limitações que lhes são impostas pelo seu aparato biológico ou pelo seu meio ambiente".

Existem outros fatores que podem determinar a diversidade da cultura humana, isto porque o homem é o único ser que rompeu com todas as suas limitações, mesmo sendo, aparentemente um animal frágil, tornou-se o pior dos predadores, pois dominou os mares, a terra e os ares, transformando-os para sua própria sobrevivência, demonstrando que não há limites para o determinismo de sua ação. Nesse sentido, podemos pensar a cultura, de acordo com Morin (2002, p. 56), como,

Um conjunto dos saberes, fazeres, regras, normas, proibições, estratégias, crenças, ideias, valores, mitos, que se transmite de geração em geração, se reproduz em cada indivíduo, controla a existência da sociedade e mantém a complexidade psicológica e social.

No entanto, sobre o termo cultura, não há uma única definição, sendo que o termo mais assertivo a ser utilizado na conjuntura contemporânea é culturas. Porém, alguns estudiosos 
estabelecem alguns conceitos para que possamos compreender as várias linhas de raciocínio e também as variações do mesmo e, o homem por sua condição enquanto "ser histórico" e incompleto, sempre estará em busca de completar-se, podendo construir-se por meio da cultura, pois há uma necessidade natural interna do indivíduo em desenvolver-se em seus contextos biológico, social e evolutivo (GEERTZ, 1989).

E, nesse desenvolvimento, o indivíduo se expressa através de suas manifestações culturais, gerando, assim, um comportamento social. Nesta concepção, Malinowski (2009, p. 45), infere que,

\begin{abstract}
A cultura consiste no conjunto integral dos instrumentos e bens de consumo, nos códigos constitucionais dos vários grupos da sociedade, nas ideias e artes, nas crenças e costumes humanos. Quer consideremos uma cultura muito simples ou primitiva, quer uma cultura extremamente complexa e desenvolvida, confrontamo-nos com um vasto dispositivo, em parte material e em parte espiritual, que possibilita ao homem fazer face aos problemas concretos e específicos que se lhe deparam.
\end{abstract}

O texto mostra que a cultura é parte inerente da vida do indivíduo, que, quase tudo tem sentido cultural e, mesmo que tal cultura seja considerada simples, primitiva, selvagem ou como quer que seja denominada, o importante é que a cultura representa os anseios, a história e a vida de uma determinada civilização, que luta para manter viva as suas tradições, costumes e valores. O que importa é que há um grande esforço por parte dos sujeitos culturais em perpetuar sacrifícios e conquistas de seus antepassados, conquistas estas, em muitos casos, defendidas com as próprias vidas.

Se observarmos ao longo da história, a cultura, ou culturas têm sido um grande campo de luta, uma vez que os únicos seres capazes de gerar culturas são os humanos, pois são possuidores de uma vasta representação de signos e significados e os únicos capazes de perpetuar conceitos, valores e crenças por milhares de anos, seja por meio da linguagem oral ou da linguagem simbólica.

Esse vasto arcabouço de representações é a diversidade cultural inerente ao ser humano, pois é preciso que nos preocupemos com a reafirmação da igualdade da natureza humana, sem contudo, esquecermos a diversidade cultural, que representa não estágios hierárquicos do ser humano, mas sim diferenças que não podem tornar-se em desigualdade ao longo do processo de desenvolvimento do homem. De acordo com Gimeno Sacristán (1999, p. 154), 
A concepção moderna da cultura deixa para a educação duas ideias-força fundamentais: a primeira, a de que a cultura é algo objetivo, externo a cada ser humano que representa "o melhor de sua história" e, por isso, vale a pena que continue e ser reproduzida; a segunda, a de que o indivíduo dignifica-se e aperfeiçoa-se com a apropriação deste legado.

A cultura como algo objetivo representa os comportamentos e vivências adquiridas por meio do mundo externo, ou seja, do ambiente onde estamos inseridos, pois estes comportamentos nos tornam aceitos dentro do grupo com o qual nos identificamos e no qual sentimos a necessidade de sermos aceitos. Em contrapartida, a concepção de que o legado cultural nos dignifica mostra que a medida que tomamos posse de uma identidade, somos levados a níveis de aceitação e de pertencimento que nos tornam cada vez mais representados por aquele legado deixado pelos nossos ancestrais, transformando nosso modo de ver o mundo através da lupa da cultura manifestada em nossa Educação.

Essa concepção moderna sobre as culturas é tão pertinente que nos leva a refletir o porquê de um cachorro, mesmo sendo criado por uma mãe gata e seus gatinhos, nunca aprender a miar, enquanto uma criança nascida na França e tirada do convívio francês, ainda recémnascida, para o convívio japonês, certamente não irá falar a língua do seu país de nascimento. Conforme Laraia (2009, p. 45), este fato nos mostra que,

O homem é o resultado do meio cultural em que foi socializado. Ele é um herdeiro de um longo processo acumulativo, que reflete o conhecimento e a experiência adquiridas pelas numerosas gerações que o antecederam. A manipulação adequada e criativa desse patrimônio cultural permite as inovações e as invenções.

Nesse contexto, não será suficiente que um indivíduo nasça dotado de altas inteligências se ele não for colocado em um ambiente que lhe proporcione o desenvolvimento de suas habilidades natas. A cultura presente no ambiente possibilitará ao sujeito desenvolver suas capacidades biológicas, uma vez que as experiências vividas ao longo da sua vida é que irão torná-lo familiarizado ou não com determinados comportamentos culturais.

Essa discussão acerca do conceito de cultura e diversidade demonstra a interdependência que há entre os dois termos e o quanto ainda há necessidade de nos debruçarmos sobre o ambíguo conceito que envolve os mesmos. Por um bom tempo, a cultura foi compreendida de forma hierárquica, onde os padrões culturais mais elevados desprezavam 
os que não estavam nesse grupo pela "falta de cultura", desqualificando-os pelo "nível cultural" ou por serem incultos, desprovidos da cultura erudita da mentalidade ocidental. Portanto, se considerarmos a cultura de forma hierarquizada, de modo algum poderemos usar o termo “culturas", pois nessa terminologia não há sobreposição cultural, enquanto o conceito de cultura por hierarquias desvaloriza a cultura das minorias. A este respeito, Bauman (2012, p. 154) afirma que,

A cultura é um esforço perpétuo para superar e remover essa dicotomia [pois,] criatividade e dependência são dois aspectos indispensáveis da existência humana, não apenas condicionando-se, mas sustentando-se mutuamente; [...] A agonia da cultura, portanto, está fadada a uma eterna continuidade; no mesmo sentido, o homem, uma vez dotado de capacidades de cultura, está fadado a explorar, a sentir-se insatisfeito com o mundo, a destruir e a criar.

Para o autor, o homem sempre terá necessidade de dar continuidade às suas criações, mas ao mesmo tempo, para sustentá-las haverá, também, a necessidade de renová-las ou condicioná-las ao tempo presente, uma vez que perpetuar suas ideias criativas é o que garante e mantém os hábitos, costumes, valores e comportamentos próprios de cada cultura.

Por sua incompletude, o ser humano buscará, em toda a sua existência, transformar ações, no sentido de completar-se, como foi o caso da escolarização, que é uma criação cultural, porém, trata-se de uma importante transformação cultural do século XX, em razão de promover a valorização e confiabilidade para a cultura e para a educação. Ou seja, para Bauman (2012), ao mesmo tempo que a cultura hierarquizada promove "oposição" entre as diferentes culturas, caracterizando-as como "requintadas" e "grosseiras", ela promove um alerta e uma preocupação, de modo que os vários sujeitos culturais em suas diversidades se tornam evidências em torno dessa dicotomia que é o mundo humano, entre o que o homem faz e o que de fato acontece com ele, transitando entre o homem e o humano.

Nesse sentido, como forma de atribuir respeito e compreensão quanto ao que representava cultura, os antropólogos, segundo Llosa (2013, p. 13) estabeleceram o conceito de que esta "era a soma das crenças, conhecimentos, linguagens, costumes, vestuários, usos; sistema de parentescos e, [...] tudo aquilo que o povo diz, faz, teme ou adora”. Embora houvesse a intenção de amenizar os preconceitos racistas e etnocêntricos, tal conceituação não foi suficiente para minorar as diferenças e acusações existentes em diversos povos e nações, tão pouco apagar a diversidade presente na humanidade, as quais permanecem ainda em nossos 
dias. E, compreender que a diversidade é parte integrante da cultura, nos parece um passo importante para que avancemos, não só nas discussões, como também nas atitudes em direção a uma igualdade de direitos e ao exercício do respeito pelas culturas, pois Pérez Tapias (2013, p. 126) afirma que:

Respeito significa reconhecer o outro, cuidando para que seus direitos não sejam menosprezados, recebendo-o no espaço comum da convivência enquanto possibilitamos a expressão de sua alteridade. É a atitude moral básica que torna possível a relação entre seres humanos, deixando para trás, de um lado, a imposição mediante a força que mantém as relações humanas na órbita do domínio, e, por outro lado, a indiferença que desvaloriza essas relações.

Portanto, quando falamos em respeito ao outro, tendo em vista a diversidade cultural, estamos falando de um comportando ético, que garante ao outro um reconhecimento de suas crenças e uma Educação para a convivência, em que a aprendizagem tenha como principal objetivo o respeito e o reconhecimento do outro enquanto igual nas suas diferenças. O respeito permite nos colocarmos no lugar do outro e, como tal, especialmente em nossa realidade brasileira plural, reconhecer a diversidade e buscarmos relacionamentos e diálogos interculturais como um processo democrático e como garantia de direitos, o que certamente promoverá consequências pedagógicas e educativas, também democráticas.

O lugar onde se entrecruzam as culturas é o espaço social onde as mesmas convivem e coexistem ao mesmo tempo, sendo fundamental que nos reconheçamos também como interlocutores desse processo, abertos ao diálogo, aceitando-nos uns aos outros em nossas diferenças, tendo este comportamento como orientador de nossas ações educativas interculturais e dialógicas. Ainda conforme Pérez Tapia (2013, p. 129), “o diálogo intercultural precisa ser livre de preconceitos, [uma vez que], esses tópicos negativos a respeito do outro que é diferente, que estigmatizam aquele a quem recaem, constituem o primeiro obstáculo que deve ser removido".

E, nesse contexto, vale ressaltar que a pluralidade cultural do nosso país vem se construindo ao longo da nossa história, não só pela própria miscigenação brasileira, que por si só, já é diversa em sua constituição, mas também pela crescente migração de refugiados nos últimos anos. Assim, temos na escola o espaço cultural por excelência onde convivem as diversidades, podendo, ou não, ser este o espaço ético e educativo para a promoção da igualdade racial, étnica, de gênero e religiosa em um diálogo intercultural, para a construção de uma 
sociedade mais crítica e mais tolerante na sua relação com o diferente.

Ademais, se considerarmos as transformações do século XX em nossa sociedade e no mundo, quando a universalização da Educação retirou o compromisso da infância e da juventude das famílias e transferiu para a escola, observaremos uma concepção que atende a um determinado tipo de sociedade, com determinados modelos de vida, hierarquias e valores. Nesse sentido, um dos principais debates dessa questão precisa ser: A que projeto cultural essa escola serve? Que ação educativa está ajudando a propagar? É fundamental reconhecermos as culturas presentes nas escolas, pois não se pode pretender uma "cultura desejável”, isto seria uma dissociação entre o cultural e o pedagógico, pois as crenças que alimentamos em relação aos educandos e a nossa ação ao educá-los, só se tornam substanciais quando consideramos os fins culturais dessa ação, para a formação integral do sujeito (GIMENO SACRISTÁN, 2002).

Por isso é urgente construirmos o discurso e as práticas para a diversidade, pois toda prática possui um determinado sentido, embora muitas vezes não estejam evidentes e, todo sujeito, individual ou coletivo, em seu discurso, está impregnado de valores, ainda que estes não estejam explícitos. Para tanto, Gimeno Sacristán (2008, p. 70) infere que "a diversidade determina a circunstância dos sujeitos como seres distintos e diferentes", e se de fato fôssemos uma sociedade democrática e tolerante respeitaríamos essas diferenças, tendo o cuidado de não transformá-las em uma desigualdade. Nesse sentido, qual seria o limite de atuação do professor em uma sala de aula, uma vez que a compreensão da diversidade é uma linha tênue entre a diferença e a desigualdade no entrecruzamento de culturas na escola.

Além de sermos únicos, enquanto ser humano, a nossa diferença está no que poderíamos ser ou onde poderíamos chegar, no acesso aos bens sociais, econômicos e culturais de forma justa e igualitária, pois novamente, Gimeno Sacristán (2008, p. 71) reforça que "todas as desigualdades são diversidade, ainda que nem toda diversidade suponha desigualdade".

O discurso da valorização da diversidade causa discordância entre os segmentos sociais e levanta opinião tão diversa quanto à diversidade e, esses comportamentos é que mantêm ou desencadeiam a desigualdade. Vale ressaltar que só existe heterogeneidade na escola porque ela também existe na sociedade, e se manifesta naturalmente no espaço educativo, onde os professores são um dos agentes capazes de colaborar em maior ou menor escala para a promoção da igualdade ou desigualdade no âmbito da escola.

A escola precisa ter um ponto de partida para trabalhar um sentido pedagógico comum, de modo a normalizar a presença da diversidade no interior da mesma, por meio de um projeto 
cultural que estabeleça quais ações diante da diversidade e também da universalidade, pois as circunstâncias podem modificar a maneira de ver a realidade, considerando que nossos hábitos, costumes (culturas) mudam o nosso modo de ver e formam ou deformam o trabalho docente, nos ensinando a ser e a não ser. Portanto, somos diversos e variados conforme as circunstâncias que nos afetam e nos tornamos indivíduos na interação como outro, com os grupos e conosco mesmos. Assim, para Gimeno Sacristán (2008, p. 75), "a escola é o primeiro espaço público vital para os indivíduos onde a vida comum obriga a restringir a contemplação dos traços individuais dos sujeitos", ou seja, mesmo na diversidade, é preciso garantir aquilo que é comum e o que é, em sua singularidade, significativamente relevante para a convivência e o desenvolvimento do bem-estar social do sujeito tanto no individual quanto no coletivo, seja na família ou na escola.

A diversidade cultural é, portanto, uma realidade no atual cenário da educação brasileira, o que nos remete a outro fato, a formação dos professores e a observação de um currículo que permita à escola considerar as diversas situações presentes em cada realidade, que não engesse os comportamentos, mas, pelo contrário, permita a flexibilização de ações que atendam às especificidades relativas ao currículo vivo e vivido na escola, de modo a assegurar, por meio das políticas públicas e da legislação, a garantia de implementação dos direitos necessários para o respeito à diversidade presente na realidade das escolas Brasil afora. O próximo tópico trará essa discussão.

\section{EDUCAÇÃO ESCOLAR INDÍGENA: LEGISLAÇÕES E DIRETRIZES NACIONAIS}

Um dos grandes marcos de emancipação cidadã é a criação de leis como política pública para garantir os direitos dos cidadãos. Entretanto, além de garantir o amplo direito aos bens sociais, culturais e históricos é preciso garantir, também, por meio de leis, o direito das minorias com suas especificidades e diferenças. Quando se trata da educação escolar indígena pode-se observar um grande avanço a partir da Constituição Federal de 1988. Faremos, então, uma breve linha do tempo das leis que referendam a educação escolar indígena, com a finalidade de obtermos um panorama dos marcos legais para essa categoria educacional.

Nesse contexto, faremos uma explanação acerca das principais mudanças e conquistas apresentadas nas principais leis que ampliaram o direito dos Índios à educação nacional, indo desde a preservação de valores até a conquista de cotas em universidades públicas. 

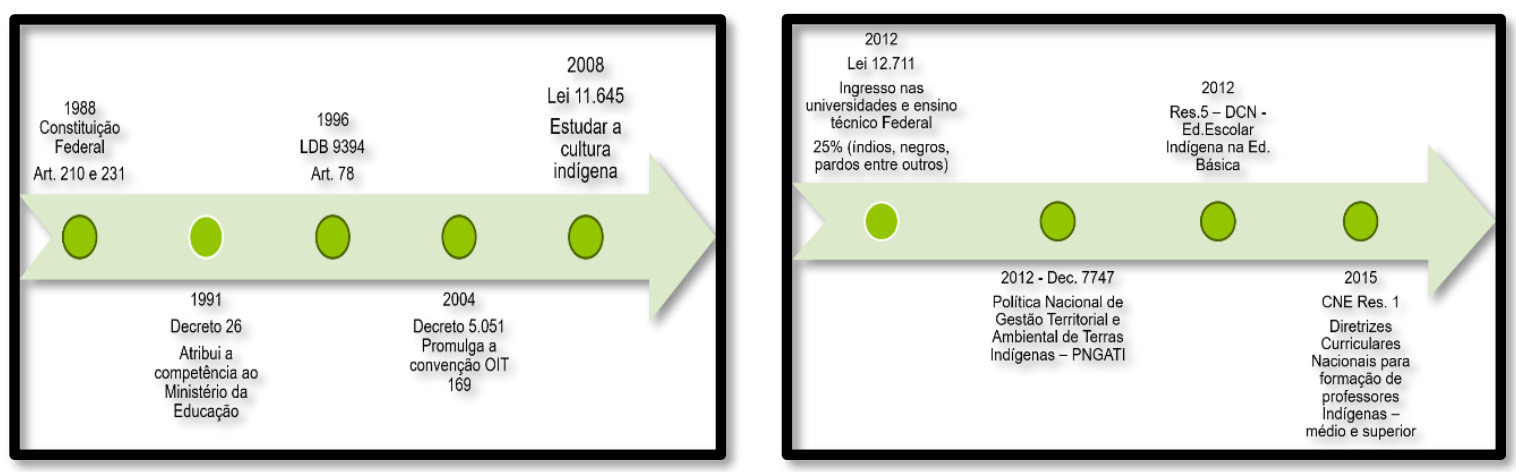

Figura 10 - Linha do Tempo da Legislação Indígena

Fonte: Disciplina Formação de Educadores na Contemporaneidade: diversidade curricular e inclusão social/ 2017.2

A Constituição Federal de 1988 foi, sem dúvida alguma, o grande marco para os povos indígenas do/no Brasil, uma vez que ela trouxe um ganho significativo, rompendo com uma tradicional posição da nossa legislação, que era o caráter integracionista previsto na Lei $n^{\circ} 6001$, de 19 de dezembro de 1973, conhecida também como Estatuto do Índio, cuja visão buscava "incorporar" os Índios à "comunidade nacional” e onde eram vistos, segundo Grupioni (s/a, p. 131), como "uma categoria étnica e social transitória fadada ao desaparecimento".

Desse modo, a partir da $\mathrm{CF} / 1988$, os Índios deixaram de ser vistos como um povo em extinção, e passaram a ter o direito às diferenças culturais próprias dos indígenas. Então, cabe a União protegê-los nos seus direitos à terra, à educação, à cultura e desporto. O artigo 210 da CF/88 (p. 124) garante que "serão fixados conteúdos mínimos para assegurar formação básica com respeito aos valores culturais, artístico nacionais e regionais", ou seja, a educação escolar precisa estar imbuída desse papel de ser o agente promotor do respeito e da formação básica do sujeito que aprende, não cabendo à escola fazer discriminação ou acepção de qualquer aluno matriculado nas classes escolares, sejam elas escolas indígenas ou não.

A CF/1988 vai além, quando em seu artigo 231 garante o reconhecimento aos Índios, à sua organização social, costumes, línguas, crenças e tradições, garantindo-lhes também o direito originário às terras ocupadas pelos Índios para que, desse modo, possam garantir sua subsistência, por meio da produção, conforme inciso $1^{\circ}$ da CF/88 (BRASIL, 1988, p. 133):

São terras tradicionalmente ocupadas pelos índios as por eles habitadas em caráter permanente, as utilizadas para suas atividades produtivas, as imprescindíveis à preservação dos recursos ambientais necessários a seu bemestar e as necessárias à sua reprodução física e cultural, segundo seus usos, 
costumes e tradições.

A Educação Escolar Indígena deve seguir essas mesmas diretrizes legais, previstas na Constituição Federal Brasileira, com vistas à manutenção da cultura tão reivindicada pelos povos indígenas. Assim sendo, vale ressaltar, o que Nascimento (2010) apresenta em sua pesquisa na Escola Indígena Baniwa e Coripaco Pamáali, localizada no Alto Rio Negro, município de São Gabriel da Cachoeira, no estado do Amazonas, pois nos parece uma referência neste sentido, onde o Projeto Político Pedagógico da escola foi elaborado de forma democrática, a partir da visão do grupo de alunos, pais e professores indígenas, destacada no texto a seguir pela visão do professor coordenador da unidade, cujo depoimento foi:

Com a construção do novo PPP, teremos mais autonomia, ele está em processo de aprovação. O documento foi construído coletivamente e logo após foi apresentado em Assembleia para avaliação dos pais. [...] A nossa Escola é pensada pelo povo Baniwa e Coripaco, não por ninguém de fora (NASCIMENTO, 2010, p. 53).

O professor coordenador declara em sua fala que só é possível construir uma escola para a diversidade com a participação de todos e cumprindo o que a Constituição Federal garante quando estabelece que os costumes e tradições, bem como a escolha dos conteúdos escolares devem estar voltados para os valores culturais, artísticos e regionais, atendendo à necessidade real, bilíngue e intercultural de cada grupo étnico, recuperando suas memórias e reafirmando sua identidade.

Em 1991, após três anos da promulgação da CF/88, o governo federal estabelece no Decreto $N^{o}$ 26, de 4 de fevereiro, para cumprir o disposto na convenção da OIT (Organização Internacional do Trabalho), no que concerne à integração das populações indígenas, decreta em seu artigo $1^{\circ}$, atribuindo ao MEC a competência para coordenar todas as ações relacionadas a Educação Indígena, em todos os níveis e modalidades de ensino, antes atribuída apenas à FUNAI. Porém, mesmo com a atribuição ao MEC, ainda há a condição de se ouvir a FUNAI, pois a educação do Índio deve ser feita com ele e não para ele.

Outro marco legal na educação escolar indígena é a LDBEN no 9394/96, pois diferentemente da LDB anterior, que nada citava sobre a educação indígena, esta nova LDB é bastante clara quanto aos direitos educacionais desta clientela. No artigo 32 , inciso $3^{\circ}$, quando se refere ao Ensino Fundamental, ela reforça o que estabelece a Carta Magna em seu artigo 210, destacando que o ensino deve ser ministrado em Língua Portuguesa, entretanto garante aos 
indígenas o uso de sua língua materna, bem como metodologias próprias para aprendizagem. Também no artigo 35-A, garante aos indígenas cursando o Ensino Médio, o direito aos estudos na língua materna. O Art. 78 desta Lei no 9394 (Brasil - MEC, 1996), estabelece que a União, por meio dos Sistemas de Ensino em parceria colaborativa com as agências federais e de assistência aos índios que fomentam a cultura, desenvolverá por meio de programas ligados ao ensino e à pesquisa, a oferta de educação escolar bilíngue (língua nativa e o português) e intercultural aos povos indígenas, cujos objetivos são:

I - Proporcionar aos índios, suas comunidades e povos, a recuperação de suas memórias históricas; a reafirmação de suas identidades étnicas, a valorização de suas línguas e ciências;

II - Garantir aos índios, suas comunidades e povos, o acesso às informações, conhecimentos técnicos e científicos da sociedade nacional e demais sociedades indígenas e não-indígenas (BRASIL, 1996).

Assim sendo, a atual LDBEN representa novas possibilidades para a educação dos povos indígenas, pois a partir dela a Educação Escolar Indígena passa a ser reconhecida como uma modalidade de ensino, cujas especificidades devem ser garantidas para a aquisição de um ensino bilíngue e intercultural, valorizando plenamente a cultura dos indígenas, reafirmando e mantendo a diversidade de cada etnia.

Com a promulgação da LDBEN 9394/96 e as inovações presentes em seu bojo, em 1998, criou-se os Referenciais para a Educação Escolar Indígena (RCNEI), cujo objetivo, sinteticamente, foi oferecer subsídios para a elaboração e implementação de programas de educação escolar que melhor atendessem aos anseios e interesses das comunidades indígenas, bem como a formação de educadores capazes de assumir as atividades e de técnicos prontos para apoiar os educadores, viabilizando as ações propostas no referencial.

Nesse contexto, o RCNEI é uma das principais políticas públicas para a educação escolar indígena, pois nela constam os fundamentos gerais e um breve histórico da educação escolar indígena, uma proposta de construção do currículo contendo orientações curriculares, a organização do trabalho escolar, implicações para a formação do professor e outros atores da escola, sobre o trabalho com os temas transversais e as línguas. Ainda oferece sugestões de como trabalhar os componentes curriculares. Entretanto, embora nos pareça uma política pública aplicável e com relevantes vantagens, a sua implementação conta com a disponibilidade dos órgãos de Estado, para o apoio e o fortalecimento dos professores indígenas, para 
juntamente com eles buscarem soluções para resoluções de problemas, que além de serem diversos no campo, são também específicos nas áreas onde cada grupo étnico se encontra, uma vez que a proposta do referencial tem como fundamento o reconhecimento da (s) multietnicidade, pluralidade e diversidade cultural; a Educação e a valorização dos conhecimentos indígenas; a autodeterminação; a comunidade educativa indígena; a Educação intercultural, comunitária, específica e diferenciada; e a preservação das características da Escola Indígena.

Em 1999, estabeleceram-se as primeiras Diretrizes Nacionais para Educação Escolar Indígena, por meio do parecer $n^{\circ}$ 14/99 e a resolução $n^{\circ}$ 03/99, as quais fixam normas para o funcionamento da escola indígena na Educação Básica. O parecer n ${ }^{\circ} 14 / 99$, faz uma referência e estabelece a diferença entre Educação Indígena e Educação Escolar Indígena. A primeira concepção é compreendida como os preceitos, hábitos, valores e saberes que são repassados de uma geração para outra, oralmente. Por esta razão, os povos indígenas foram, ao longo da história, considerados ágrafos, pois não possuíam a cultura alfabética, vindo a ter contato com esta a partir da interação com a cultura de escola do não índio. A segunda concepção surge devido ao fato de que, uma vez inseridos no convívio do não índio, houve a necessidade de criação de um espaço onde o índio pudesse repassar seus saberes, resguardando suas especificidades e características. Assim, com a perda do caráter integracionista, assegurado na $\mathrm{CF} / 88$, garantiu-se ao indígena uma escola que mantivesse uma educação diferenciada, bilíngue e intercultural.

A Resolução N. 03 de 10 de novembro de 1999, fixa as Diretrizes para o funcionamento das escolas indígenas, explicitadas em seu Artigo $1^{\circ}$ (Brasil - CNE/CEB, 1999, s.p.):

Estabelecer, no âmbito da educação básica, a estrutura e o funcionamento das Escolas Indígenas, reconhecendo-lhe a condição de escolas com normas e ordenamento jurídico próprias, e fixando as Diretrizes curriculares do Ensino intercultural e bilíngue, visando à valorização plena das culturas dos povos indígenas e à afirmação e manutenção de sua diversidade étnica.

Ademais, esta resolução dá outras providências também quanto ao currículo para escola indígena, quanto à formação de professores para a escola indígena, bem como da participação representativa dos professores indígenas em todas as decisões que se referem à escola indígena. Portanto, as diretrizes estabelecem a fundamentação e conceituações da educação indígena, expressas na criação da categoria Escola Indígena, na definição da esfera administrativa, na 
formação do professor indígena, no currículo e sua flexibilização, bem como na flexibilização das exigências e das formas contratação de professores indígenas que atuarão para construção de uma escola diferenciada, bilíngue e intercultural.

Em 2001, a Lei $n^{\circ} 10.172$ se apresenta como outro instrumento legal para a Educação Escolar Indígena é o Plano Nacional de Educação (PNE) é dedicado, no documento, um capítulo para tratar desta modalidade da educação básica. O plano apresenta um breve histórico acerca da educação indígena, apresenta, também, as diretrizes e, por fim, trata dos objetivos e metas para a educação escolar indígena. Um destaque relevante está no fato de se criar a categoria "escola indígena" para poder garantir o bilinguismo e a interculturalidade referidas tanto na $\mathrm{CF} / 88$, quanto na $\mathrm{LDB}$ e RCN e também nas Diretrizes para a educação escolar indígena. Para tanto, mais uma vez, cabe aos estados criar meios e condições para que a escola indígena se estabeleça, se desenvolva e receba o apoio necessário e fundamental para o alcance das metas e objetivos previstos no PNE, sendo que a formação de professores ainda é um dos maiores desafios, pois é preciso garantir cursos que preparem esses professores para atuar no contexto bilíngue, uma vez que, conforme afirma Ribeiro (1996, p. 282), “a língua constitui um dos elementos mais persistentes da cultura; todavia, também ela reflete forçosamente as experiências vividas no grupo". Assim sendo, fica evidente que os professores da escola indígena precisam ser aqueles que dominam a língua materna e a Língua Portuguesa, pois com a língua materna se perpetua a cultura e com a Língua Portuguesa se estabelece a comunicação para sobrevivência cultural sustentável.

O Decreto $n^{\circ} 5.051$ de 19 de abril de 2004, que promulga a Convenção $\mathrm{n}^{\circ} 169$ da Organização Internacional do Trabalho (OIT) sobre povos indígenas e tribais teve sua primeira versão em Genebra, em 27 de junho de 1989, entrando em vigor internacionalmente em 05 setembro de 1991, e sendo adotado no Brasil 25 de julho de 2003. Este decreto lembra os termos da Declaração Universal dos Direitos Humanos, o Pacto Nacional dos Diretos Econômicos, Sociais e Culturais e o Pacto Internacional dos Direitos Civis e Políticos e também, os inúmeros instrumentos internacionais que tratam acerca da prevenção da discriminação. Além de observar as normas internacionais, este decreto reconhece o anseio dos povos indígenas em tomarem o controle de suas instituições, bem como gerenciar seus próprios interesses com a garantia de que os governos assumirão a responsabilidade de desenvolver ações que atendam às necessidades específicas e própria de cada grupo étnico. Neste contexto, destacamos os artigos a seguir: 
Artigo $6^{\circ}$ - Os governos devem consultar os povos interessados, mediante procedimentos apropriados e por meio das instituições representativas, cada vez que sejam previstas medidas legislativas ou administrativas suscetíveis de afetá-los diretamente;

Artigo $7^{\circ}$ - Os povos indígenas têm o direito de escolher suas, próprias prioridades no que diz respeito ao processo de desenvolvimento, na medida em que ele afete as suas vidas, crenças, instituições e bem-estar espiritual, bem como as terras que ocupam ou utilizam de alguma forma, e de controlar, na medida do possível, o seu próprio desenvolvimento econômico, social e cultural; os governos deverão zelar pela participação dos povos interessados; Artigo $8^{\circ}$ - Ao aplicar a legislação nacional aos povos interessados deverão ser levados na devida consideração seus costumes desde que eles não sejam incompatíveis com os direitos fundamentais definidos pelo sistema jurídico nacional nem com os direitos humanos internacionalmente reconhecidos (BRASIL - OIT, 2004).

Ao observarmos os artigos supracitados, podemos verificar que esta legislação possibilita aos povos indígenas maior liberdade de atuação, preservação de suas crenças e bens espirituais e culturais, bem como o gerenciamento de seus bens econômicos. Entretanto, nos vemos novamente sob a boa vontade dos governantes, pois deles dependem as condições favoráveis para implementação das leis e, nesse caso, nem sempre as prioridades dos povos indígenas serão as prioridades dos governos.

Em 2008, a Lei 11.645 alterou a LDBEN 9394/96, no que concerne às bases do currículo oficial de ensino, incluído a obrigatoriedade do tema "História e cultura afro-brasileira e indígena". Isto significa dizer que esta lei estabelece a necessidade de se abordar esta temática em todas as disciplinas tanto do Ensino Fundamental, quanto no Ensino Médio, conforme verificamos no texto abaixo:

Art. 26-A._Nos estabelecimentos de ensino fundamental e de ensino médio, públicos e privados, torna-se obrigatório o estudo da história e cultura afrobrasileira e indígena.

$\S 1^{\circ}$ O conteúdo programático a que se refere este artigo incluirá diversos aspectos da história e da cultura que caracterizam a formação da população brasileira, a partir desses dois grupos étnicos, tais como o estudo da história da África e dos africanos, a luta dos negros e dos povos indígenas no Brasil, a cultura negra e indígena brasileira e o negro e o índio na formação da sociedade nacional, resgatando as suas contribuições nas áreas social, econômica e política, pertinentes à história do Brasil.

$\S 2^{\circ}$ Os conteúdos referentes à história e cultura afro-brasileira e dos povos indígenas brasileiros serão ministrados no âmbito de todo o currículo escolar, em especial nas áreas de educação artística e de literatura e história brasileiras (BRASIL - MEC, 2008). 
A obrigatoriedade prevista nesta lei compreende um avanço na história do currículo e uma oportunidade para que índios e negros tenham, de alguma maneira, uma espécie de retratação histórica pelos anos que ficaram de fora do currículo e consequentemente dos livros didáticos. Tanto os negros quanto os índios possuem uma história de segregação e invisibilidade, sendo apresentados nos livros didáticos com uma concepção distorcida, em um aparecimento tão rápido, como se estivessem prestes a desaparecer de vez do contexto de sua própria história.

Em 2012, outra conquista foi o Decreto 7.747 que institui a Política Nacional de Gestão Territorial e Ambiental de Terras Indígenas, o PNGATI, que possui como um dos objetivos da sua criação o reconhecimento e respeito às crenças, usos, costumes, línguas, tradições e especificidades de cada povo indígena; e a proteção e fortalecimento dos saberes, práticas e conhecimentos dos povos indígenas e de seus sistemas de manejo e conservação dos recursos naturais. Além disso, o $7^{\circ}$ eixo do decreto discute a capacitação, formação, intercâmbio e educação ambiental, uma vez que entre as preocupações está em:

Qualificar, capacitar e prover a formação continuada das comunidades e organizações indígenas sobre a PNGATI; fortalecer e capacitar as comunidades e organizações indígenas para participarem na governança da PNGATI, prevenção e controle de queimadas e incêndios; e promover ações voltadas ao reconhecimento profissional, à capacitação e à formação de indígenas para a gestão territorial e ambiental no ensino médio, no ensino superior e na educação profissional e continuada (BRASIL - PNGATI, 2012).

Esse decreto reforça a necessidade de se respeitar as diversidades presentes na Educação dos indígenas, nas suas particularidades, mas também nos mostra o quanto a territorialidade faz parte do processo identitário do índio, como um caminho para desenvolvimento e a sustentabilidade cultural. Ainda, em 2012, a Resolução No 5, de 22 de junho de 2012, considera a Constituição Federal, diversas diretrizes e pareceres para definir Diretrizes Curriculares Nacionais para a Educação Escolar Indígena na Educação Básica. Esta resolução aborda de maneira detalhada os objetivos, princípios e organização da escola indígena, bem como do projeto pedagógico, contemplando currículo, avaliação e professores. Esta pauta-se nos princípios da igualdade social, da diferença, da especificidade, do bilinguismo, da interculturalidade que são os fundamentos da Educação Escolar Indígena. Pode-se considerar que essas Diretrizes foram um marco na educação escolar indígena, pois considerou todas as 
resoluções, pareceres e decretos, fazendo uma síntese das conquistas alcançadas e transformando em uma lei que com diretrizes claras para a educação escolar indígena, expressas no Artigo $2^{\circ}$ dos objetivos:

I - Orientar as escolas indígenas de educação básica e os sistemas de ensino da União, dos Estados, do Distrito Federal e dos Municípios na elaboração, desenvolvimento e avaliação de seus projetos educativos;

II - Orientar os processos de construção de instrumentos normativos dos sistemas de ensino visando tornar a Educação Escolar Indígena projeto orgânico, articulado e sequenciado de Educação Básica entre suas diferentes etapas e modalidades, sendo garantidas as especificidades dos processos educativos indígenas;

III - Assegurar que os princípios da especificidade, do bilinguismo e multilinguismo, da organização comunitária e da interculturalidade fundamentem os projetos educativos das comunidades indígenas, valorizando suas línguas e conhecimentos tradicionais;

IV - Assegurar que o modelo de organização e gestão das escolas indígenas leve em consideração as práticas socioculturais e econômicas das respectivas comunidades, bem como suas formas de produção de conhecimento, processos próprios de ensino e de aprendizagem e projetos societários;

V - Fortalecer o regime de colaboração entre os sistemas de ensino da União, dos Estados, do Distrito Federal e dos Municípios, fornecendo diretrizes para a organização da Educação Escolar Indígena na Educação Básica, no âmbito dos territórios etnoeducacionais;

VI - Normatizar dispositivos constantes na Convenção 169, da Organização Internacional do Trabalho, ratificada no Brasil, por meio do Decreto Legislativo $n^{\circ} 143 / 2003$, no que se refere à educação e meios de comunicação, bem como os mecanismos de consulta livre, prévia e informada;

VII - Orientar os sistemas de ensino da União, dos Estados, do Distrito Federal e dos Municípios a incluir, tanto nos processos de formação de professores indígenas, quanto no funcionamento regular da Educação Escolar Indígena, a colaboração e atuação de especialistas em saberes tradicionais, como os tocadores de instrumentos musicais, contadores de narrativas míticas, pajés e xamãs, rezadores, raizeiros, parteiras, organizadores de rituais, conselheiros e outras funções próprias e necessárias ao bem viver dos povos indígenas;

VII - Zelar para que o direito à educação escolar diferenciada seja garantido às comunidades indígenas com qualidade social e pertinência pedagógica, cultural, linguística, ambiental e territorial, respeitando as lógicas, saberes e perspectivas dos próprios povos indígenas (BRASIL - CEB, 2012).

Diante dos objetivos expostos, constatamos todas as dimensões que envolvem a educação escolar indígena, contempladas para garantir a integralidade da formação escolar do Índio. A valorização dos espaços administrativos dentro dos sistemas de ensino, a construção do PPP, o respeito às especificidades, ao bilinguismo, aos costumes, à espiritualidade, bem como a todas as particularidades necessárias e favoráveis ao bem-estar social, econômico e 
cultural do indígena.

Por conseguinte, em 2015, o CNE cria a resolução $N^{\circ}$ 01, de 7 de janeiro de 2015, define as Diretrizes Curriculares Nacionais para formação de professores indígenas, para formação inicial em nível superior, todas as licenciaturas e também segunda licenciatura e cursos formação pedagógica para graduados e também para formação continuada. Esta tem por objetivo regulamentar os programas e cursos destinados à formação inicial e continuada de professores indígenas no âmbito dos respectivos sistemas de ensino, suas instituições formadoras e órgãos normativos. Assim, esta conquista foi um marco para que se cumpra o maior desafio enfrentado pelos indígenas, que é a formação de professores também indígenas, que dominem a língua materna e sejam sensíveis às questões específicas das realidades das comunidades escolares indígenas.

\section{CONSIDERAÇÕES}

Pensar a cultura em um sentido objetivo traduz as experiências vividas na realidade na qual estamos inseridos. A concepção de que a bagagem cultural nos torna dignos, demonstra que à medida que nos revestimos de uma identidade para sermos melhor aceitos no grupo, nos tornamos cada vez mais representados por este e pelo legado cultural deixado pelo mesmo. Isto transforma nosso modo de ver o mundo, pois o filtro que utilizamos é aquele manifesto por aquela mesma cultura, ou seja, a nossa Educação.

Para além da cultura, a diversidade cultural é parte do atual cenário nacional da educação brasileira, em que pese a formação de professores e a adesão de um currículo que considere tal diversidade presente na escola, sem engessar os comportamentos e as metodologias a serem trabalhadas. Ao contrário disto, que seja um currículo flexível e que possibilite ações conforme as especificidades em relação ao currículo vivido na realidade de cada escola, para garantir a necessária implementação dos direitos fundamentais, respeitando a diversidade presente nas mais diversas escolas no contexto contemporâneo brasileiro.

Portanto, refletir sobre a educação escolar indígena, enquanto modalidade de ensino da educação básica, traz a prerrogativa de um currículo que contenha tanto os conhecimentos da formação geral quanto os da específica. Na extensão de nosso país, existem indígenas tanto em áreas escolares exclusivamente indígenas, mas também temos alunos indígenas inseridos em escolas urbanas e/ou rural não indígenas. Neste contexto, há necessidade de reconhecermos que 
precisamos promover interações entre as diretrizes para a educação escolar indígena e os documentos do currículo da educação básica nacional, ou seja, o que está previsto para esta modalidade da educação brasileira e assegurado dentro das diretrizes e bases curriculares nacionais. Assim sendo, precisamos pensar cada vez mais sobre as inclusões dentro do currículo para as diversidades do nosso alunado, tanto dos "antigos" quanto dos "novos" brasileiros.

\section{REFERÊNCIAS}

BAUMANN, Zigmunt. Ensaios sobre o conceito de cultura. Tradução Carlos Aberto Medeiros. Rio de Janeiro: Zahar, 2012.

BHABHA, Homi. O local da Cultura. Belo Horizonte: UFMG, 1998.

BRASIL. Constituição da República Federativa do Brasil. Gabinete da Presidência: Brasília, 1988.

BRASIL. Decreto n. ${ }^{\circ} 26$ de 04/12/1991 - OIT. Presidência da República. Casa Civil. Subchefia de assuntos jurídicos. Disponível em: www.planalto.gov.br. Acesso em: 24 abr. 2019.

BRASIL. Lei n. ${ }^{\circ}$ 9.394/96. Lei de Diretrizes e Bases da Educação Nacional. Conselho Nacional de Educação: Brasília, 1996.

BRASIL. Lei n. ${ }^{0}$ 10.172. Plano nacional de Educação. Conselho Nacional de Educação: Brasília, 2014.

BRASIL. Lei n. ${ }^{\circ}$ 11.645. História e cultura afro-brasileira e indígena. Conselho Nacional de Educação: Brasília, 2008.

BRASIL. MEC. PARECER N. ${ }^{\circ}$ 14/99 - Diretrizes Curriculares Nacionais da Educação Escolar Indígena. Conselho Nacional de Educação. Brasília, 1999.

BRASIL. MEC. Proposta para a Base Nacional Comum da Formação de Professores da Educação Básica. Ministério da Educação: Brasília, DF, 2018. Disponível em: www.mec.gov.br. Acesso em: 01 out. 2019.

BRASIL. MEC. Referencial Curricular Nacional para as Escolas Indígenas. MEC/SEF, Brasília, 1998.

BRASIL. MEC. Resolução N. ${ }^{\circ} 05$. Diretrizes Curriculares da Educação Escolar Indígena. Conselho Nacional de Educação: Brasília, 2012. 
BRASIL. MEC. Resolução N. ${ }^{\circ}$ 01. Diretrizes Curriculares para a Formação de Professores Indígenas. Conselho Nacional de Educação: Brasília, 2015.

CHIZZOTTI, Antônio. Pesquisa em ciências humanas e sociais. 11. ed. São Paulo: Cortez, 2010.

GEERTZ, Clifford. A interpretação das culturas. Rio de Janeiro Livros Técnicos e Científicos, 1989.

GIMENO SACRISTÁN, José. Poderes instáveis em educação. Porto Alegre: Artmed, 1999.

GIMENO SACRISTÁN, José. Educar e conviver na cultura global: as exigências da cidadania. Trad. Ernani Rosa. Porto Alegre: Artmed, 2002.

GIMENO SACRISTÁN, José. A construção do discurso da diversidade e as suas práticas. In: PARASKEVA, João M. Educação e poder: abordagens críticas e pós-estruturais. Portugal: Edições Pedago, 2008. p. 69-95.

GRUPIONI, Luis Donisete Benzi; SECCHI, Darci; GUARANI, Vilmar. Legislação escolar indígena. Painel 05. Vol. 14, p. 129-203. Disponível em:

http://portal.mec.gov.br/seb/arquivos/pdf/vol4c.pdf. Acesso em: 24 abr. 2019.

HALL, Stuart. A identidade cultural na pós-modernidade. 11. ed. Rio de Janeiro: DP\&A, 2011.

JOHNSON, Richard. O que é, afinal, Estudos Culturais? In: SILVA, Tomaz Tadeu da (Org.). O que é, afinal, Estudos Culturais? 4. ed. Belo Horizonte: Autêntica, 2010. p. 12-52.

LARAIA, Roque de B. Cultura: um conceito antropológico. 23. ed. Rio de Janeiro: Jorge Zahar, 2009.

LLOSA, Mário Vargas. Breve discurso sobre a cultura. In: MACHADO, Cassiano Elek (Org.). Pensar a cultura. Porto Alegre: Arquipélago Editorial, 2013. p. 11-31.

MALINOWSKI, Bronislaw. Uma teoria científica de cultura. Tradução Marcelina Amaral. Lisboa, Portugal: Edições 70, 2009.

MORIN, Edgar. Os sete saberes necessários à educação do futuro. São Paulo: Cortez, 2002.

NASCIMENTO, Maria Rosemi Araújo do. Educação Intercultural e Ensino de Ciências: construção de conceitos em ciências naturais na escola indígena Baniwa e Coripaco Pamáali, no Alto Rio Negro. Orientadora: Maria Auxiliadora de Souza Ruiz, 2010. 92 f. Dissertação (Mestrado em Educação) - Universidade Estadual do Amazonas, Manaus, 2010. 
PÉREZ TAPIAS, José Antônio. Educar a partir da interculturalidade: exigências curriculares para o diálogo entre culturas. In: GIMENO SACRISTÁN, José. Saberes e incertezas do currículo. Tradução Alexandre Salvaterra. Porto Alegre: Penso, 2013. p. 126-136.

RIBEIRO, Darcy. Os índios e a civilização: a integração das populações indígenas no Brasil moderno. São Paulo: Companhia das Letras, 1996.

Recebido em: 01/07/2020

Aprovado em: 11/09/2020 